\title{
Experimental and Theoretical Analysis of Axial Magnetic Coupling under Steady-State and Transient Operation
}

\author{
Thierry Lubin, Smail Mezani, and Abderrezak Rezzoug
}

\begin{abstract}
This paper investigates the steady-state and the transient performances of an axial magnetic coupling by using analytical formulas issued from an analytical model based on a two-dimensional approximation for the magnetic field distribution (mean radius model). From the magnetic field expression, simple analytical formulas are derived for computing the pull-out torque and the torsional stiffness of the coupling as a function of the geometrical parameters. Here, a special attention is given to the overload torque condition during the transient which lead to the loss of synchronism for the coupling. Moreover, radial and angular misalignment conditions are also studied. In order to study the accuracy of the proposed analytical model, the results are compared with those obtained from 3D finite element simulations and measurements.
\end{abstract}

Index Terms-- Analytical model, magnetic field, axial coupling, permanent magnets, pull-out torque, transient performance.

\section{NOMENCLATURE}

$\begin{array}{ll}R_{l} & \text { Inner radius of the magnets } \\ R_{2} & \text { Outer radius of the magnets } \\ R_{e} & \text { Mean radius of the magnets } \\ h & \text { Magnets thickness } \\ e & \text { Air-gap thickness } \\ \alpha & \text { PMs pole-arc to pole-pitch ratio } \\ p & \text { Pole-pair number } \\ \delta & \text { Torque angle } \\ B_{r} & \text { Remanence of the permanent magnets } \\ K & \text { Torsional stiffness }\end{array}$

\section{INTRODUCTION}

$\mathrm{M}$ AGNETIC couplings are used to transmit torque from primary driver to a load without any mechanical contact. As the torque could be transmitted across a separation wall, magnetic couplings are well suited for use in isolated systems. Among the advantages of this type of coupling compared to mechanical couplings is the self protection against the overload (pull-out torque). Moreover, magnetic couplings tolerate shaft misalignment.

As shown in Fig. 1, the studied axial magnetic coupling consists of two discs equipped with sector-shaped permanent magnets (rare-earth magnets) and separated by a small airgap. The magnets are axially magnetized and are arranged to obtain alternately north and south poles. Soft-iron yokes are used to close the flux. Through magnetic interaction, the torque applied to one disc is transferred through an air-gap to the other disc.

T. Lubin, S. Mezani and A. Rezzoug are with the Groupe de Recherche en Electrotechnique et Electronique de Nancy (GREEN), Université de Lorraine, 54506 Nancy, France (e-mail: thierry.lubin@univ-lorraine.fr).
In order to predict the steady state and the transient performance of magnetic couplings or PMs actuators, an accurate knowledge of the air-gap flux density distribution is necessary. The flux density can be evaluated by analytical methods using 3D formulation or approximate 2D formulations [1]-[21] or by numerical techniques like finite elements [22]-[25]. Analytical methods generally require much less computational time than numerical ones and can provide closed-form solution for the torque [5], [19], [20] which can be used in optimization codes.

While the steady-state performance of magnetic couplings or magnetic gears is widely studied in the literature, only little attention is given to transient performances [26], [27] and experimental data are practically nonexistent [28], [29].

The purpose of this paper is to analyze the steady-state (pull-out torque) and the transient performance (start-up, sudden change in load torque, and overload conditions) of an axial magnetic coupling by using analytical formulas for the pull-out torque and the torsional stiffness. Compared to [29], a special attention is given here to overload torque conditions which lead to the loss of synchronism for the coupling. In order to study the accuracy of the proposed model, the results are compared with those obtained from 3D finite element simulations and measurements.

\section{ANALYTICAL CALCULATION OF THE MAGNETIC FIELD}

Because of the three-dimensional nature of the magnetic field distribution, rigorous computation of the torque requires a full three-dimensional analysis [1]-[3], [7]. However, in order to simplify the analysis and to carry out simple formulas for the torque and the torsional stiffness, the $3 \mathrm{D}$ problem of Fig. 1 is reduced to a $2 \mathrm{D}$ one by introducing a cylindrical cutting surface at the mean radius of the magnets $R_{e}=\left(R_{1}+R_{2}\right) / 2$ on which the flux density will be computed. Fig. 2 shows the resulting $2 \mathrm{D}$ model which makes the axial magnetic coupling equivalent to a linear magnetic coupling.

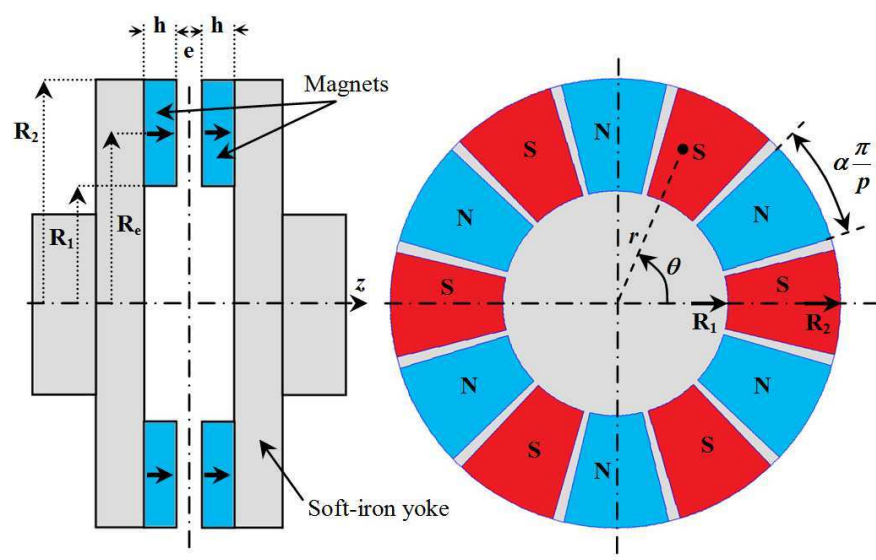

Fig. 1. Geometry of the studied axial magnetic coupling $(p=6)$. 


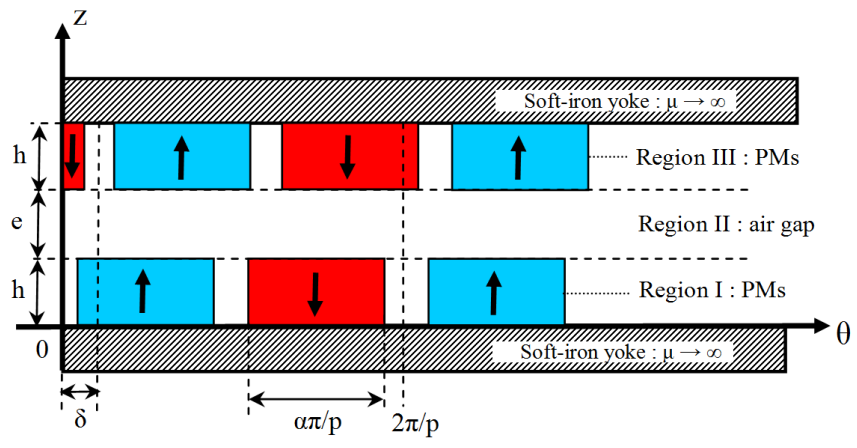

Fig. 2. 2D model of the axial magnetic coupling at the mean radius of the magnets $R_{e}=\left(R_{1}+R_{2}\right) / 2$.

With this approach, we neglect the radial component of the magnetic field and we consider that the axial and tangential components do not depend on the $r$-coordinate. Moreover, we consider that the iron yokes have infinite magnetic permeability (which gives homogeneous Neumann conditions on their boundaries). The magnets are axially magnetized with a relative recoil permeability $\mu_{r}=1$.

Detailed developments for the magnetic field calculation in the different regions of Fig. 2 are given in [20] and will not be repeated here. In this paper, only the method and the most important relations are remembered. Compared to [20], the model has been simplified by only considering the first harmonic term of the magnetic field distribution. As it will be shown, this hypothesis leads to simple expressions for the axial and tangential components of the flux density in the airgap which allows computing very quickly the pull-out torque.

\section{A. Magnetic Vector Potential in the Air-Gap}

A magnetic vector potential formulation has been used in [20] to study the problem shown in Fig. 2. With this formulation, we have to solve the following partial differential equations in the magnets and air-gap regions

$$
\begin{aligned}
& \frac{1}{R_{e}^{2}} \frac{\partial^{2} A_{i}}{\partial \theta^{2}}+\frac{\partial^{2} A_{i}}{\partial z^{2}}=-\frac{\mu_{0}}{R_{e}} \frac{\partial M_{z}}{\partial \theta} \text { with } i=I \text { and } I I I \\
& \frac{1}{R_{e}^{2}} \frac{\partial^{2} A_{I I}}{\partial \theta^{2}}+\frac{\partial^{2} A_{I I}}{\partial z^{2}}=0 \quad \text { in the air-gap }
\end{aligned}
$$

where $\mu_{0}$ is the permeability of the vacuum and $M_{z}$ is the axial magnetization of the magnets. Due to the periodicity of the magnetic field distribution, the studied domain has been limited by $0 \leq \theta \leq 2 \pi / p$. The axial magnetization $M_{z}$ can be expressed in Fourier's series and replaced in (1). If we consider only the first space harmonic term of the magnetization distribution, we can write

$$
M_{z}(\theta)=\frac{4 B_{r}}{\pi \mu_{0}} \sin \left(\alpha \frac{\pi}{2}\right) \sin (p(\theta-\delta))
$$

where $\delta$ (torque angle) is the relative angular position between the magnets of region I and region III as shown in Fig. 2. By considering the interface and boundary conditions for the magnetic field, we obtain the general solution of the magnetic vector potential in the air-gap region

$$
\begin{aligned}
& A_{I I}(\theta, z)= \\
& \left(-a^{I I} \frac{\cosh (k(z-h-e))}{k \sinh (k e)}+b^{I I} \frac{\cosh (k(z-h))}{k \sinh (k e)}\right) \cos (p \theta) \\
& +\left(-c^{I I} \frac{\cosh (k(z-h-e))}{k \sinh (k e)}+d^{I I} \frac{\cosh (k(z-h))}{k \sinh (k e)}\right) \sin (p \theta)
\end{aligned}
$$

where $k=p / R_{e}$ and $a^{I I}, b^{I I}, c^{I I}$ and $d^{I I}$ are the integration constants. These integration constants can be determined from the interface conditions between the regions as explained in [20].

\section{B. Magnetic Flux Density in the Air-Gap}

The axial and tangential components of the magnetic flux density in the air-gap can be deduced from the magnetic vector potential (4) using

$$
B_{I I z}=-\frac{1}{R_{e}} \frac{\partial A_{I I}}{\partial \theta} \quad \text { and } \quad B_{I I \theta}=\frac{\partial A_{I I}}{\partial z}
$$

To compute the pull-out torque from the Maxwell stress tensor, we have to know the flux density expression on a line in the air-gap region. The simplest expression for the flux density is obtained at $z=h+e / 2$ (middle of the air-gap). Moreover, with the first harmonic hypothesis, we know that the torque presents a sinusoidal characteristic and so we have to compute only its maximum value.

From (4) and (5) and after some calculus to obtain the values of the integration constants $a^{I I}, b^{I I}, c^{I I}$ and $d^{I I}$, the axial and tangential components of the magnetic flux density in the middle of the air-gap for $\delta=\pi / 2 p$ are given by

$$
\begin{aligned}
& B_{I I z}(\theta)=\frac{4 \sqrt{2} B_{r}}{\pi} \sin \left(\alpha \frac{\pi}{2}\right) \frac{\sinh (a) \cosh ((1+v) a)}{\sinh (2(1+v) a)} \sin \left(p \theta-\frac{\pi}{4}\right) \\
& B_{I I \theta}(\theta)=\frac{4 \sqrt{2} B_{r}}{\pi} \sin \left(\alpha \frac{\pi}{2}\right) \frac{\sinh (a) \sinh ((1+v) a)}{\sinh (2(1+v) a)} \sin \left(p \theta-\frac{\pi}{4}\right)
\end{aligned}
$$

where

$$
a=p \frac{h}{R_{e}} \quad \text { and } \quad v=\frac{e}{2 h}
$$

As expected, we can observe from (6) and (7) that the axial and tangential flux density waves are in phase when we consider the pull-out torque position.

By using (6) and (7), it is now possible to derive analytical formulas for the pull-out torque and for the torsional stiffness of the axial coupling. The next sections concern the analysis of the steady state and the transient performance of the coupling with experimental validations.

\section{STEADY-STATE ANALYSIS}

\section{A. Pull-Out Torque Expression}

The pull-out torque is obtained by the Maxwell stress tensor where a line at the middle of the air-gap is taken as the integration path

$$
T_{\max }=\frac{R_{2}^{3}-R_{1}^{3}}{3 \mu_{0}} \int_{0}^{2 \pi} B_{I I \theta}(\theta) B_{I I z}(\theta) d \theta
$$


Incorporating (6) and (7) into (9), we can derive a simple formula for the pull-out torque which depends directly on the geometrical parameters.

$$
T_{e}=T_{\max } \sin (p \delta)
$$

with

$$
T_{\max }=\frac{16}{3 \pi} \frac{B_{r}^{2}}{\mu_{0}} R_{2}^{3}\left(1-\left(\frac{R_{1}}{R_{2}}\right)^{3}\right) \sin ^{2}\left(\alpha \frac{\pi}{2}\right) \frac{\sinh ^{2}(a)}{\sinh (2(1+v) a)}
$$

The formula (11) has been used in [20] for optimal design of the coupling given in Table I.

\section{B. 3D FE Simulations and Measurements}

For the steady-state analysis, the formula (11) has been compared with both 3-D FEM simulations and experimental results. For the 3-D finite element simulations, we have used COMSOL $^{\circledR}$ multiphysics software. For the experimental validation, we have manufactured an axial magnetic coupling prototype using sector type $\mathrm{NdFeB}$ magnets glued on iron yokes. The thickness of the iron yokes $(1 \mathrm{~cm})$ has been chosen to avoid magnetic saturation. The geometrical parameters of the prototype are those of Table I.

Fig. 3 shows the axial magnetic coupling placed on the test bench. The axial coupling is inserted between two electrical machines (DC motors, 3kW, 1500rpm). In fig. 3, the air-gap value is $e=9.5 \mathrm{~mm}$. The air-gap length has been set by inserting non-magnetic plates of known thickness between the two discs. Figs. $4 \mathrm{a}$ and $4 \mathrm{~b}$ show respectively a photograph and a block-scheme representation of the test bench arrangement for the static torque measurement. As shown in Fig. 4b, the static torque was measured thanks to weights $(250 \mathrm{~g}, 500 \mathrm{~g}, 1 \mathrm{~kg})$ suspended to a rod $(1=1 \mathrm{~m})$ locked to one rotor, the other being fixed. The relative angular position $\delta$ was measured using an incremental encoder with a resolution of 4096 pulses/revolution (precision of 0.088 degrees) and the data was transferred into a computer.

Fig. 5 shows the pull-out torque as a function of the airgap length obtained with 3D finite elements analysis and with the 2D analytical model (11). As expected for this type of device, the 2D analytical prediction gives higher values for the pull-out torque as compared to 3D FE analysis [20]. This is mainly due to the $3 \mathrm{D}$ effects which are not taken into account in the proposed model (the radial dependence of the magnetic field is not considered). The error on the pull-out torque prediction ranges from $22 \%$ for $e=2 \mathrm{~mm}$ to $31 \%$ for $e=10 \mathrm{~mm}$.

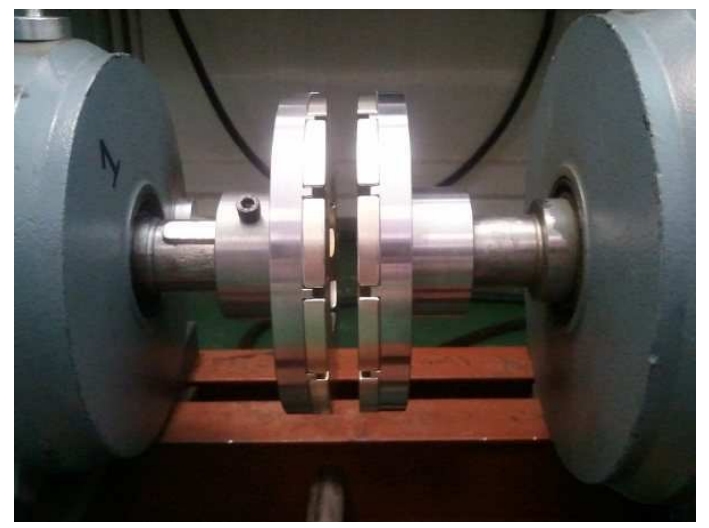

Fig. 3. Axial magnetic coupling prototype placed on the test bench $(e=$ $9.5 \mathrm{~mm})$.

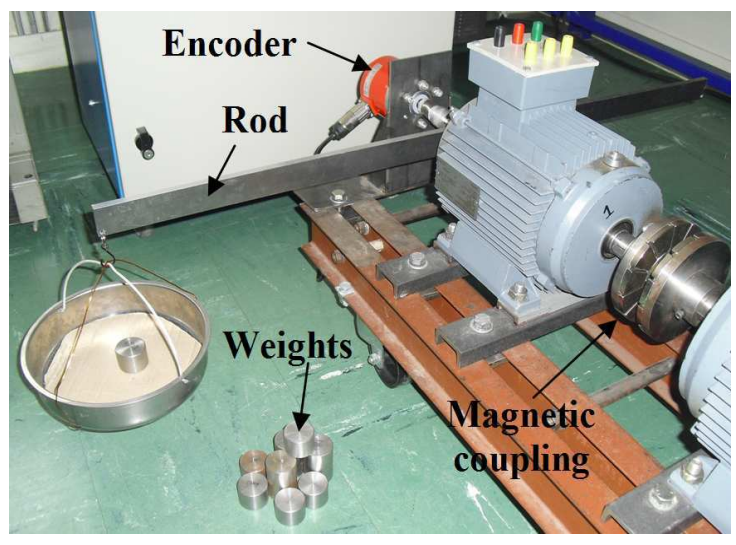

(a)

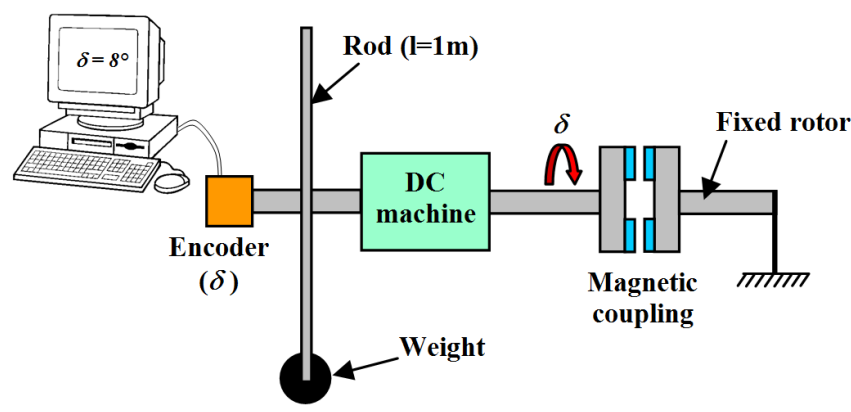

(b)

Fig. 4. Experimental setup for the static torque measurement: (a) photograph, (b) block-scheme representation (top view).

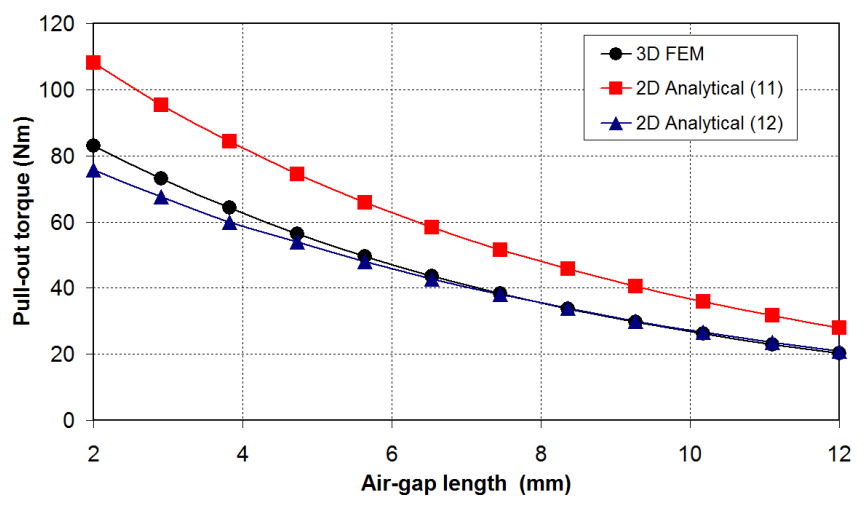

Fig. 5. Pull-out torque versus the air-gap length: 3D FEM and 2D analytical results.

TABLE I

PARAMETERS OF THE STUDIED AXIAL COUPLING

\begin{tabular}{lll}
\hline \hline \multirow{2}{*}{ Symbol } & \multicolumn{1}{c}{ Quantity } & \multicolumn{1}{c}{ value } \\
& & $30 \mathrm{~mm}$ \\
$R_{l}$ & Inner radius of the magnets & $60 \mathrm{~mm}$ \\
$R_{2}$ & Outer radius of the magnets & $45 \mathrm{~mm}$ \\
$R_{e}$ & Mean radius of the magnets & $7 \mathrm{~mm}$ \\
$h$ & Magnets thickness & variable \\
$e$ & Air-gap length & 0.9 \\
$\alpha$ & PMs pole-arc to pole-pitch ratio & 6 \\
$p$ & Pole-pairs number & $1.25 \mathrm{~T}$ \\
$B_{r}$ & Remanence of the permanent magnets & \\
\hline
\end{tabular}


In order to analyze the error on the torque prediction of the 2D model, a parametric study has been carried out. For a magnet thickness $h=7 \mathrm{~mm}$ and an air-gap $e=4 \mathrm{~mm}$, we vary $R_{1}, R_{2}$ and $p$ in the following intervals:

- $R_{2}=[40 \mathrm{~mm}$ to $140 \mathrm{~mm}$ ] with a step of $20 \mathrm{~mm}$ (6 values),

- $R_{1}=\left[0.2 \times R_{2}\right.$ to $\left.0.8 \times R_{2}\right]$ with a step of $0.1 \times R_{2}$ ( 7 values),

$-p=[2$ to 8$]$ with a step of 1 (7 values).

This corresponds to 294 combinations.

Then, for each value of $R_{2}$, we have 49 evaluations (3D FE) of the pull-out torque $T_{3 D}$, the maximal value being noted $T_{3 D \text {-max }}$. Among these 49 calculations, we have only considered the representative values for which $T_{3 D} / T_{3 D-\max }>$ 0.7. Indeed, we always look in practice to the most favorable configurations which maximize the torque.

A non-dimensional number $\lambda=\pi\left(R_{2}+R_{I}\right) /\left(2 p\left(R_{2}-R_{l}\right)\right)$ is introduced. It allows comparing the magnet height $\left(R_{2}-R_{I}\right)$ and the mean pole-pitch $\pi\left(R_{2}+R_{l}\right) / 2 p$.

We have defined a correction factor of the $2 \mathrm{D}$ model by $k_{c}=T_{\max } / T_{3 D}$, where $T_{\max }$ is given by (11). Fig.6 gives the variation of $k_{c}$ versus $\lambda$. It can be seen that the values of $k_{c}$ ranges between 0.7 and 0.8 for the most representative cases. Furthermore, one can see that the optimal values of $\lambda$ that maximize the torque transmission capabilities of the coupling are between 0.3 and 0.8 . Notice that these optimal values of $\lambda$ can also be predicted with the formula (11) as indicated in [20].

Hence, for engineering purposes, a correction factor $k_{c}$ based on the results of Fig. 6, can be introduced to improve the precision of the torque formula (11)

$$
T_{\max c}=k_{c} T_{\max } \quad \text { with } \quad k_{c} \approx 0.75
$$

where $T_{\max }$ is given by (11). As it can be observed in Fig. 5, a simple correction coefficient in the analytical torque expression leads to acceptable results whatever the air-gap length.

Figs. 7 show the comparison between the measured values of the static torque (Fig. 4) and the calculated ones by using the 2D analytical models and 3D FEM. Here, four values of the air-gap length were considered ( $e=4 \mathrm{~mm}, e=9.5 \mathrm{~mm}, e=$ $13 \mathrm{~mm}$ and $e=20 \mathrm{~mm}$ ). It can be observed in Fig. 7 that the measurements are in good agreement with both the 3D FE simulations and the 2D corrected analytical model given by (12).

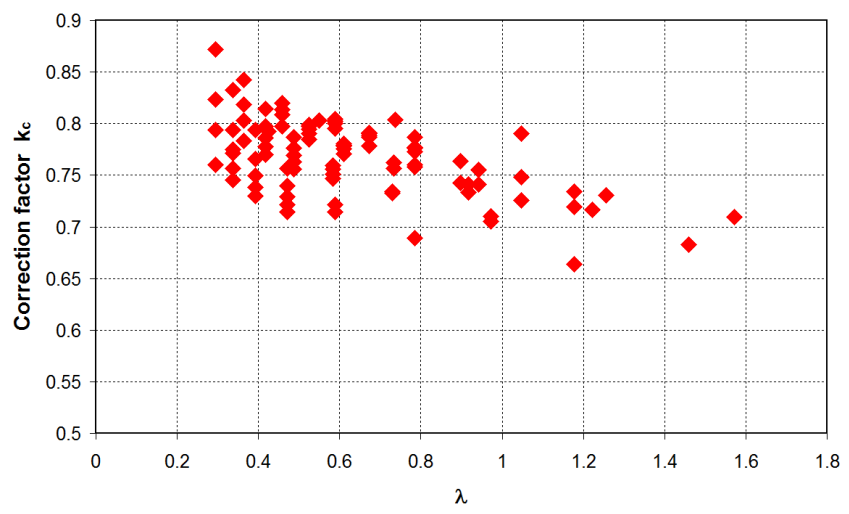

Fig. 6. Correction factor $\mathrm{k}_{\mathrm{c}}$ (for $e=4 \mathrm{~mm}$ ).

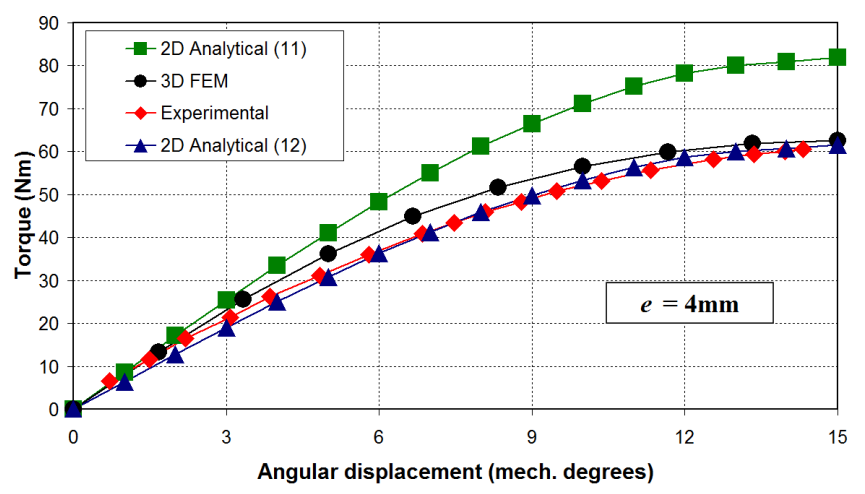

(a)

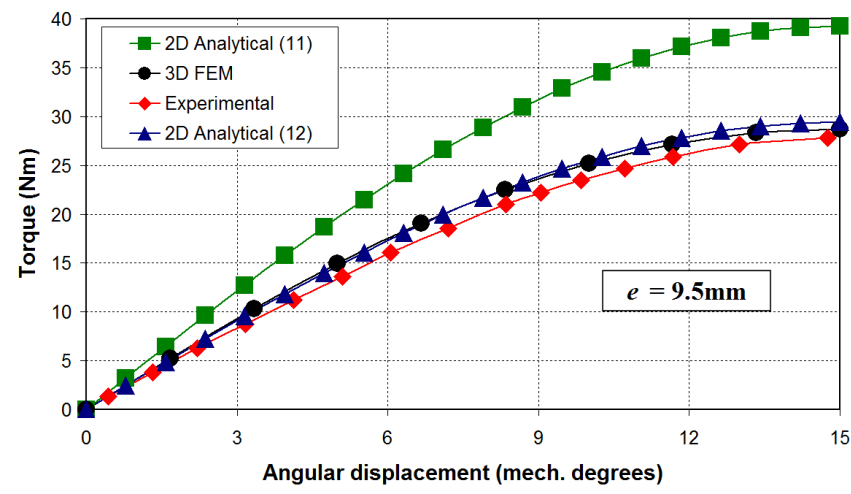

(b)

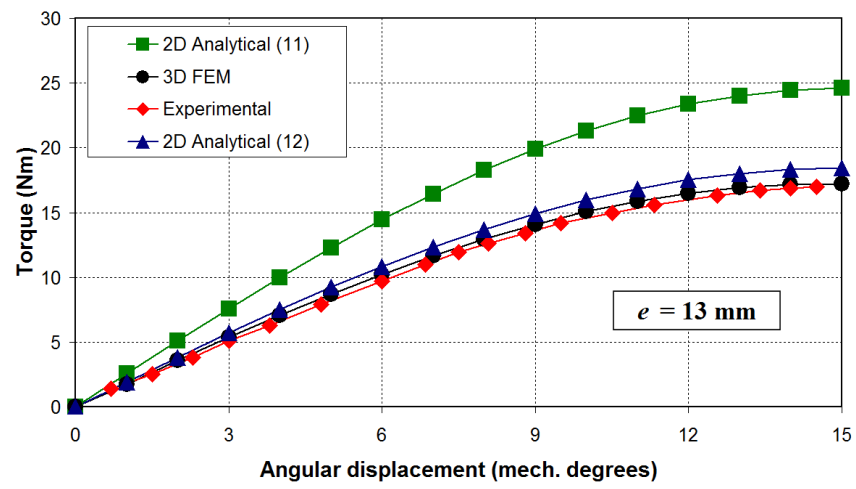

(c)

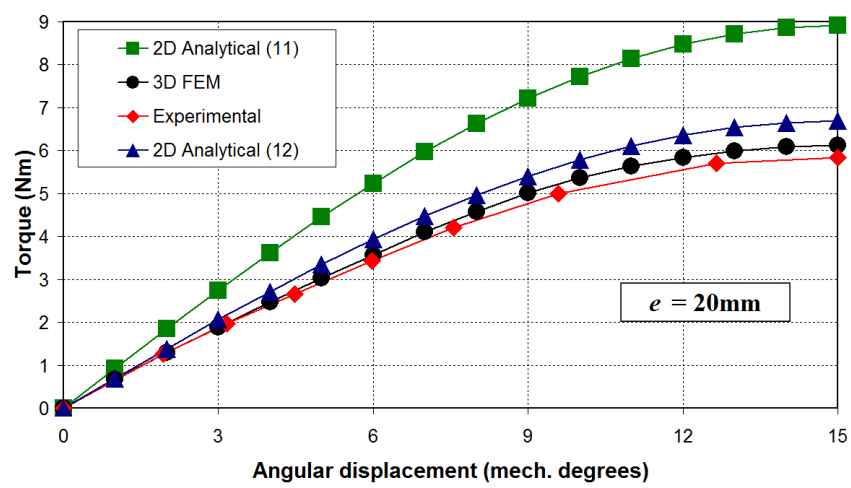

(d)

Fig. 7. Measured and computed static torque versus the angular displacement $\delta$ : (a) $e=4 \mathrm{~mm}$, (b) $e=9.5 \mathrm{~mm}$, (b) $e=13 \mathrm{~mm}$, (b) $e=20 \mathrm{~mm}$.

\section{Tolerance to radial and angular misalignments}

Fig. 8 shows the influence of the radial and angular misalignments on the static torque of the designed coupling (results obtained with $3 \mathrm{D} \mathrm{FE}$ analysis). It can be seen that a radial misalignment of $d=10 \mathrm{~mm}$ leads to a reduction of the 
maximum torque of about $11 \%$ compared to the case where $d=0$. On another hand, an angular displacement of $\beta=1^{\circ}$ leads to a reduction of about $25 \%$ of the maximum torque compared to the healthy situation $(\beta=0)$. It can be concluded that the torque transmission capabilities of the coupling are more sensitive to angular misalignments.

\section{TRANSIENT ANALYSIS}

\section{A. Torsional Stiffness Expression}

In transient analysis of magnetic couplings or magnetic gears [26]-[29], one of the most important parameter is the torsional stiffness $K$ (in $\mathrm{Nm} / \mathrm{rad}$ ). It is equal to the initial slope of the torque vs. position curves shown in fig. 7 . This coefficient depends on the geometrical parameters of the coupling and more particularly on the air-gap value $e$. From (10) and (12), we can obtain an analytical expression for $K$

$$
K=p T_{\max c}
$$

Fig. 9 shows the variation of the torsional stiffness $K$ versus the air-gap length. As expected, the coefficient $K$ decreases with the air-gap length (the coupling is more elastic with a large air-gap). For an air-gap value of $4 \mathrm{~mm}$, the torsional stiffness of the studied magnetic coupling is around $370 \mathrm{Nm} / \mathrm{rad}$. For comparison, rigid or semi-flexible mechanical couplings present torsional stiffness of more than $5000 \mathrm{Nm} / \mathrm{rad}$.

\section{B. Equations of Motion}

The transient analysis of the magnetic coupling is obtained from the equation of motion for rotating rigid bodies. Fig. 10 shows the scheme of the test bench. The DC motor rotates at $\Omega_{m}$ and the load runs at $\Omega_{l}$.

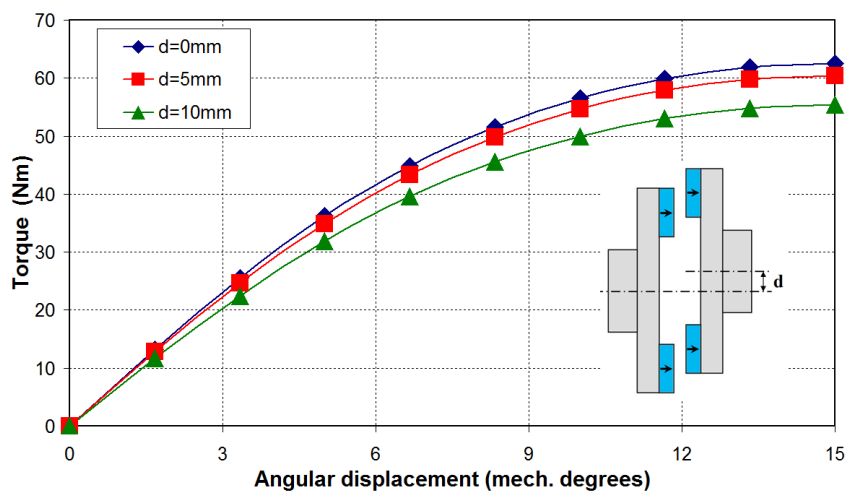

(a)

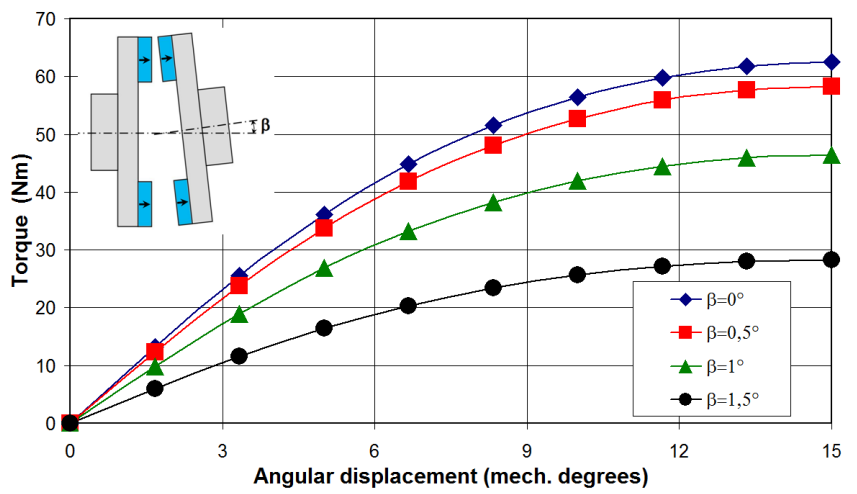

(b)

Fig. 8. Effects of misalignment on the static torque for $\mathrm{e}=4 \mathrm{~mm}$ : (a) radial misalignment (b) angular misalignment.

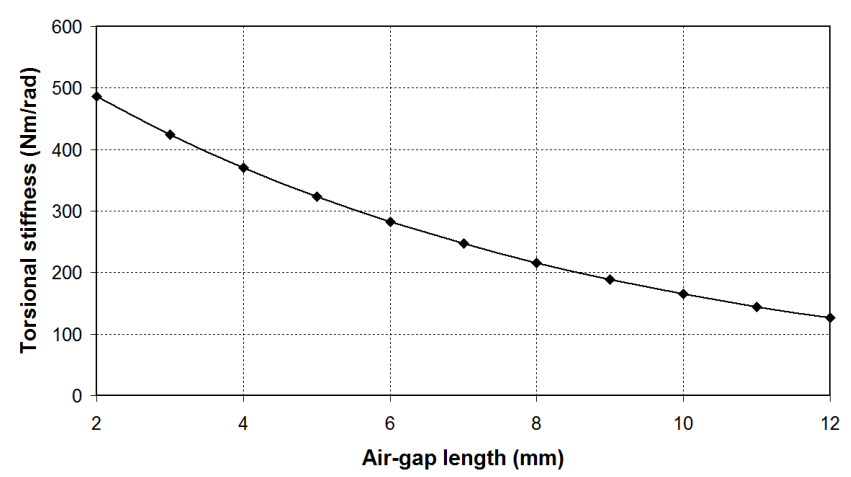

Fig. 9. Torsional stiffness $(K)$ versus the air-gap length for the studied magnetic coupling.

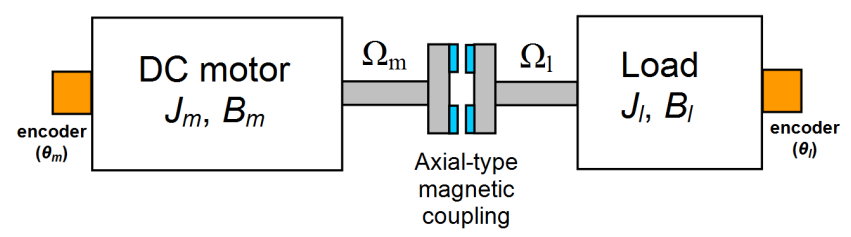

Fig. 10. Scheme of the test bench.

In steady state condition, the two speeds are the same. Two encoders (4096 pulses/revolution) have been placed on the test bench to measure the relative angular position between the DC motor and the load and to measure the speed on both sides of the coupling during the transient.

The motion equations are given by

$$
\begin{gathered}
J_{m} \frac{d \Omega_{m}}{d t}+B_{m} \Omega_{m}=T_{D C}-T_{e} \\
J_{l} \frac{d \Omega_{l}}{d t}+B_{l} \Omega_{l}=T_{e}-T_{\text {load }}
\end{gathered}
$$

where $J_{m}$ and $B_{m}$ denote the total moment of inertia and the coefficient of friction of the DC motor and one part of the axial coupling, $J_{l}$ and $B_{l}$ denote the total moment of inertia and the coefficient of friction of the other part of the axial coupling and the load. $T_{D C}$ is the DC motor torque and $T_{\text {load }}$ is the external load torque. The torque of the magnetic coupling (10) and (12) can be re-written as follows

$$
T_{e}=T_{\max c} \sin \left(p\left(\theta_{m}-\theta_{l}\right)\right)
$$

where $\Omega_{m}=d \theta_{m} / d t, \Omega_{l}=d \theta_{l} / d t$.

\section{Sudden Application of Load Torque}

In order to study the transient behavior of the coupling, a first test consists to block one part of the magnetic coupling (the DC motor part is locked i.e. $\theta_{m}=0, \Omega_{m}=0$ ) and to apply a sudden variation on the load torque (supplementary weight from a wire attached at the end of a rod as shown in Fig. 4). In this case, the motion equation (14) becomes

$$
J_{l} \frac{d^{2} \theta_{l}}{d t^{2}}+B_{l} \frac{d \theta_{l}}{d t}=-T_{\max c} \sin \left(p \theta_{l}\right)+T_{\text {load }}
$$

If we consider a small variation of the load torque $\Delta T_{\text {load }}$ and a value of $\theta_{l}$ near to zero, (16) can be rewritten as a second-order linear differential equation

$$
J_{l} \frac{d^{2} \theta_{l}}{d t^{2}}+B_{l} \frac{d \theta_{l}}{d t}+K \theta_{l}=\Delta T_{\text {load }}
$$

where $K$ is given by (13). We can define the damping ratio $\xi$ and the oscillation period $T$ as 


$$
\xi=\frac{B_{l}}{2 \sqrt{K J_{l}}} \quad T=2 \pi \sqrt{\frac{J_{l}}{K}}
$$

The load torque variation and the moment of inertia $J_{l}$ (obtained by the Huygens' theorem) depend on the total weight $m+\Delta m$ attached to the rod (rod of length $l=1 m$ ) as

$$
\Delta T_{\text {load }}=\frac{l}{2} g \Delta m \text { and } J_{l}=J+(m+\Delta m)\left(\frac{l}{2}\right)^{2}
$$

where $g=9.81 \mathrm{~ms}^{-2}, J$ is the load inertia without weight $(J=$ $\left.0.01 \mathrm{~kg} \cdot \mathrm{m}^{2}\right), \quad m$ is the initial weight, and $\Delta m$ is the supplementary weight applied at $t=0 \mathrm{~s}$.

Fig. 11 shows the variation of the load angle $\theta_{l}$ (simulation results obtained with (17) and experimental results) when we apply a load torque step of $5 \mathrm{Nm}$ at $t=0 \mathrm{~s}$ that corresponds to a weight of around $\Delta m=1 \mathrm{~kg}$ (the initial torque is fixed to $14.7 \mathrm{Nm}$ i.e. $m=3 \mathrm{~kg}$ ). The moment of inertia $J_{l}$ given by (19) is then equal to $1.01 \mathrm{~kg} \cdot \mathrm{m}^{2}$. The torsional stiffness of the magnetic coupling is $K=$ $370 \mathrm{Nm} / \mathrm{rad}$ (air-gap of $4 \mathrm{~mm}$ ). The oscillation period can be estimated by (18) at $T=0.33 \mathrm{~s}$ that is closed to the experimental results $(T=0.35 \mathrm{~s})$ given in Fig. 11. As shown in Fig. 11, the initial and final load angle can also be predicted with a very good precision by using the analytical $\operatorname{model}\left(\sin \theta_{l}=T_{\text {load }} / T_{\text {maxc }}\right)$.

\section{Transient Performance During Start-Up}

The transient start-up performance is assessed by running the DC motor from standstill (at $\mathrm{t}=0 \mathrm{~s}$ ) to the speed of 400 rpm under no-load condition. Figures 12, 13 and 14 show the speed responses for three values of the air-gap length $(e=$ $4 \mathrm{~mm}, e=13 \mathrm{~mm}$ and $e=20 \mathrm{~mm}$ ). The simulation results have been computed with (14) and (15). Experimental and simulation results show clearly that there are speed oscillations with time delays between the two rotors of the magnetic coupling. As expected from (18), the oscillation period $T$ increases when the torsional stiffness of the coupling decreases (i.e. the air-gap increases) as shown in Fig. 12 to Fig. 14. These speed oscillations have to be taken into account for servomechanism applications.

During the starting, there are some power losses in the permanent magnets and iron yokes (eddy-current). This is due to the speed difference between the two rotors. The eddy-current causes additional 'damping' torque (asynchronous torque) which can be included in the transient analysis of the coupling [28] by increasing the damping ratio (18). The computation of the eddy-current could be done analytically with the resistance limited assumption [30], [31] or by finite element simulations. Anyway, this study is complex and is outside the objective of the paper.

Fig. 15 shows the variation of the angular displacement between the two sides of the coupling $\Delta \theta=\theta_{m}-\theta_{l}$ during startup under no-load condition (corresponding to the speed variations given in Fig. 14). As shown in Fig. 15, $\Delta \theta$ reaches a value of $15.7^{\circ}$ (at $t=0.025 \mathrm{~s}$ ) which is slightly greater than its maximum value before instability $\left(\Delta \theta_{\max }=15^{\circ}\right.$ for $\left.p=6\right)$. However, we can observe that the coupling doesn't lose the synchronism for this test. This can be explained by the additional torque (asynchronous torque) due to eddy-current as indicated previously. After the transient, the displacement angle reduces to a zero mean value for this no-load test, Fig. 15 .

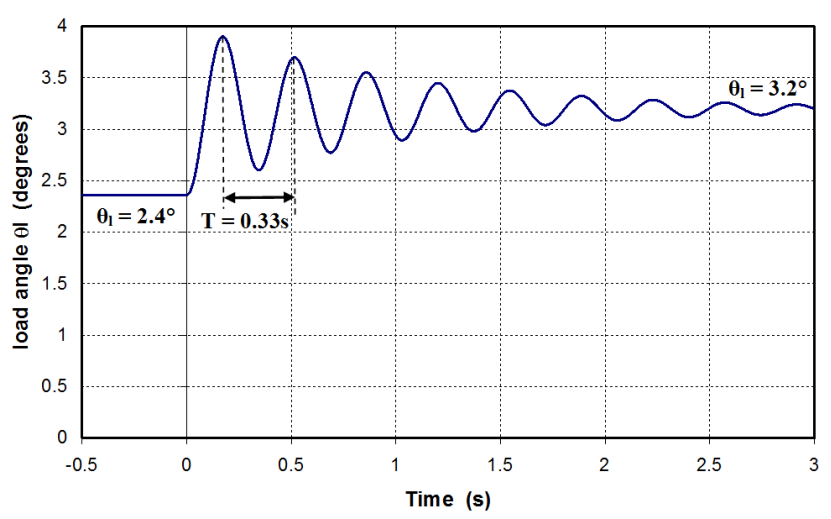

(a)

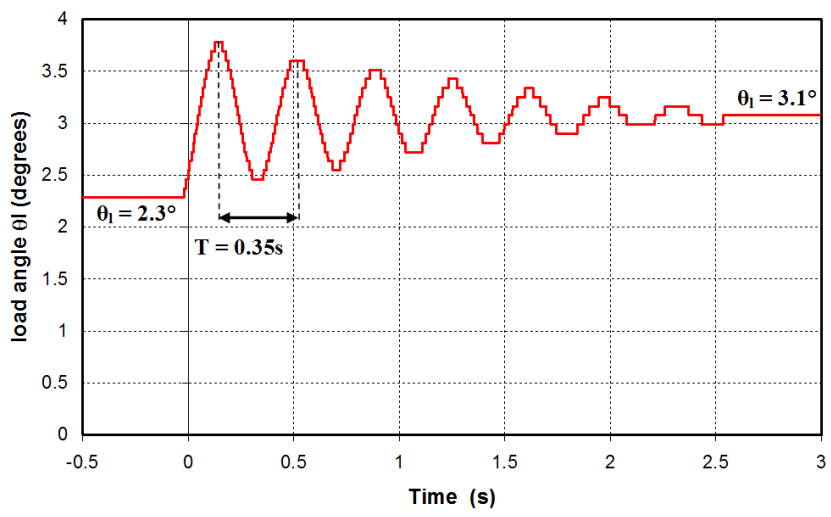

(b)

Fig. 11. Load angle oscillations due to a sudden variation of the load torque $\left(\Delta T_{\text {load }}=5 \mathrm{Nm}\right)$ for $e=4 \mathrm{~mm}$ and $K=370 \mathrm{Nm} / \mathrm{rad}$ : (a) simulation result, (b) experimental result.

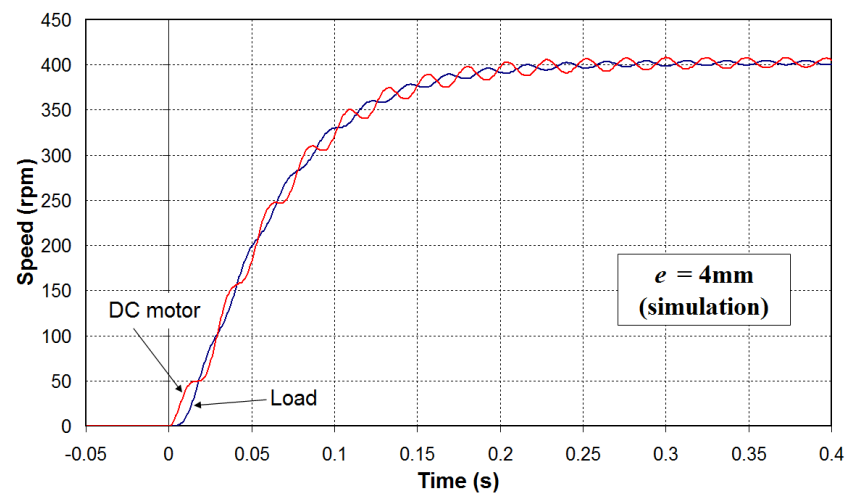

(a)

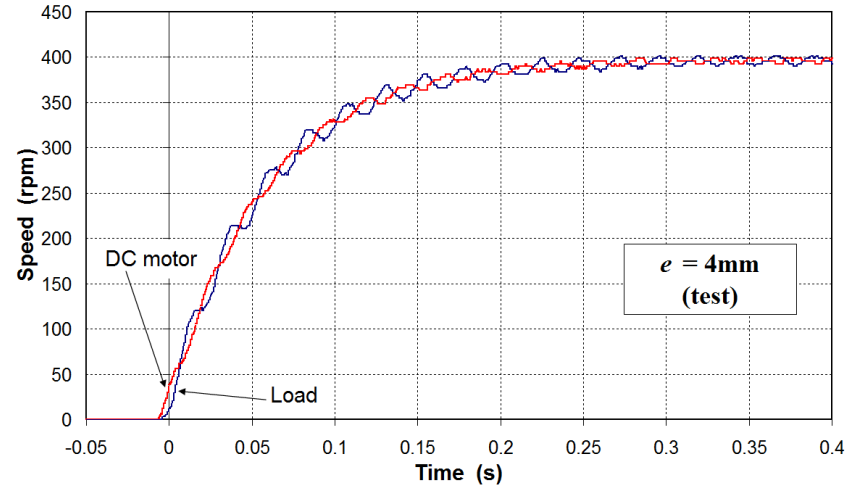

(b)

Fig. 12. Speed responses with torsional stiffness $K=370 \mathrm{Nm} / \mathrm{rad}(e=$ $4 \mathrm{~mm}$ ): (a) simulation result (b) experimental result. 


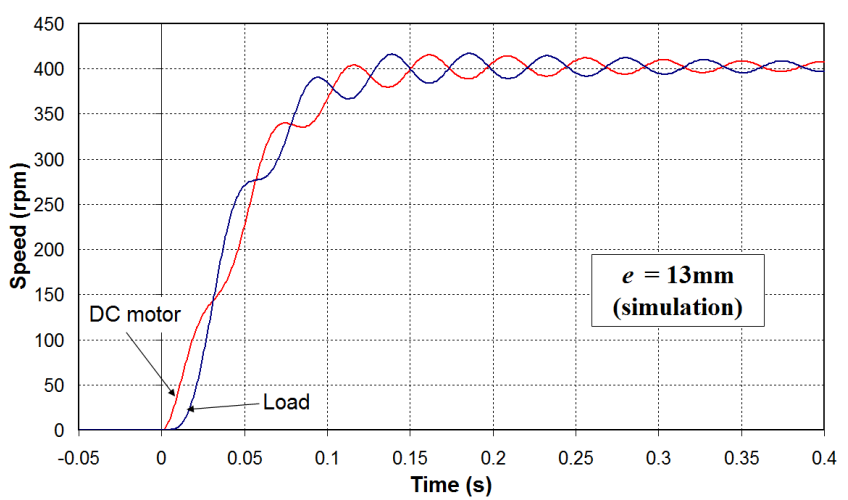

(a)

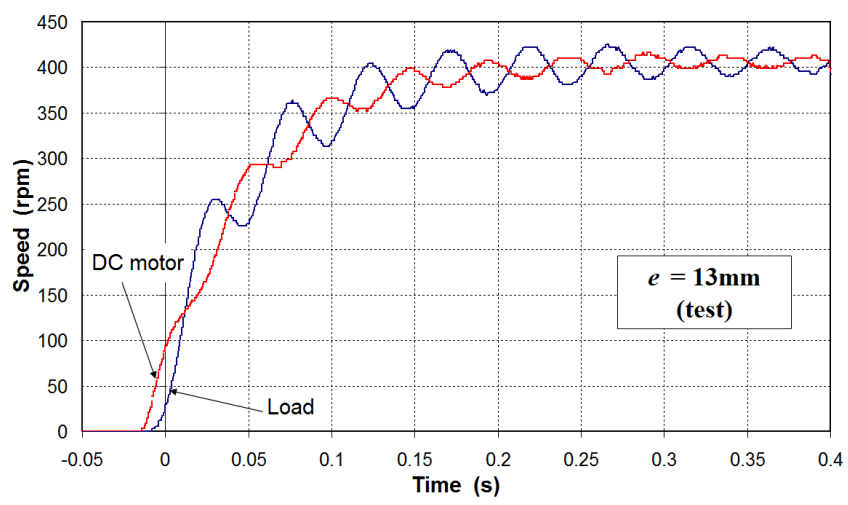

(b)

Fig. 13. Speed responses with torsional stiffness $K=105 \mathrm{Nm} / \mathrm{rad}(e=$ $13 \mathrm{~mm}$ ): (a) simulation result (b) experimental result.

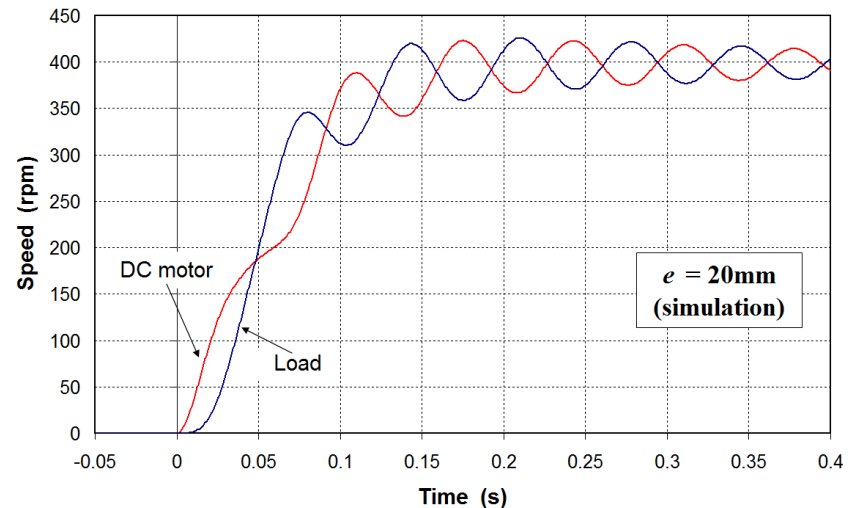

(a)

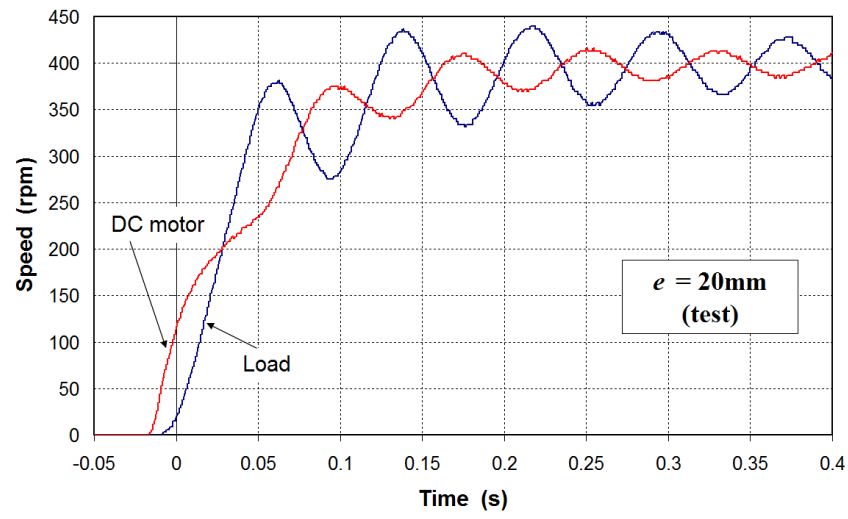

(b)

Fig. 14. Speed responses with torsional stiffness $K=42 \mathrm{Nm} / \mathrm{rad}(e=$ 20mm): (a) simulation result, (b) experimental result.

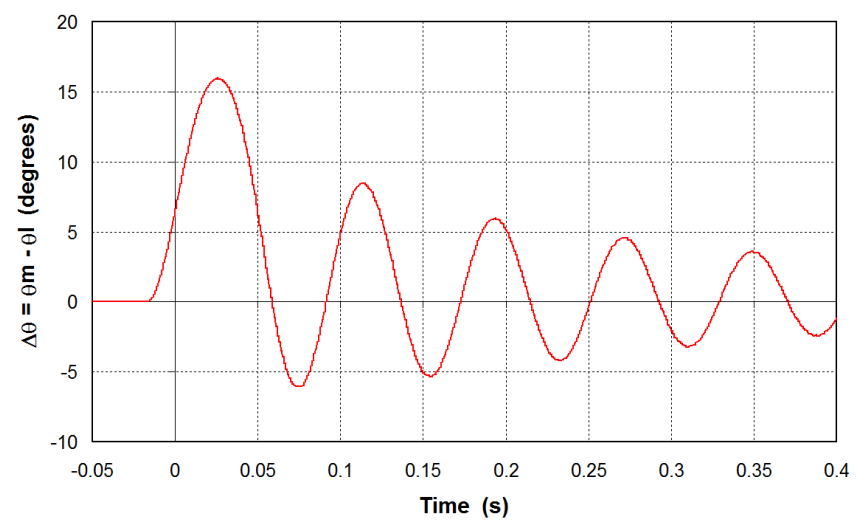

Fig. 15. Angular displacement between the two sides of the coupling during starting under no-load condition, experimental result $(e=20 \mathrm{~mm})$.

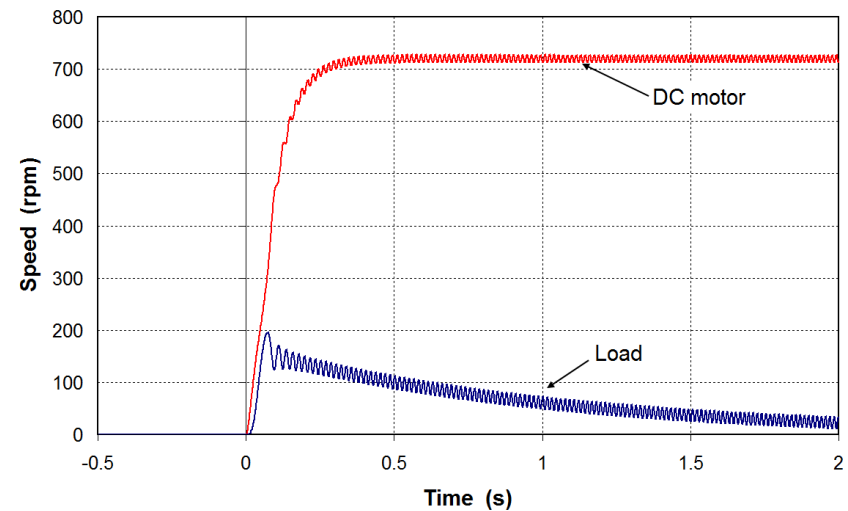

(a)

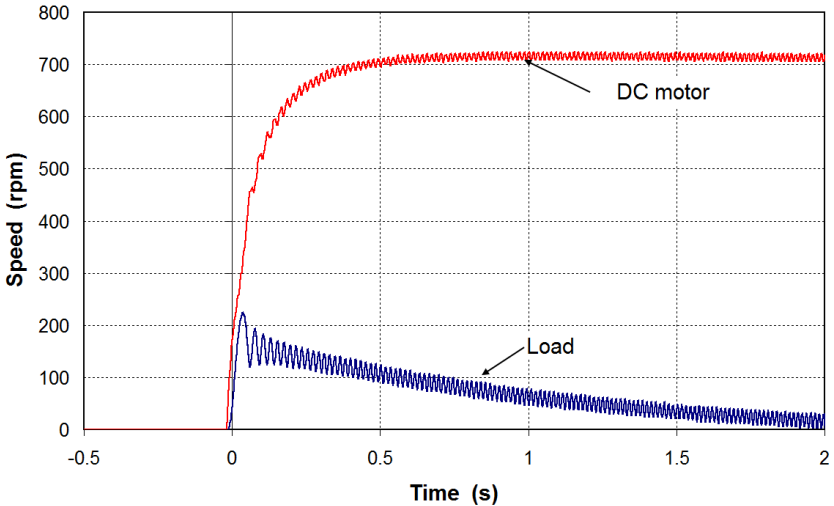

(b)

Fig. 16. Loss of synchronism caused by an abrupt start-up of the DC motor (from standstill to $725 \mathrm{rpm}$ ): (a) simulation, (b) experimental results.

Another test with a larger speed variation (standstill to $725 \mathrm{rpm}$ ) has been performed and the results (simulation and experimental) are given in Fig. 16. For this test, the air-gap value is fixed to $e=20 \mathrm{~mm}$. It can be seen in Fig. 16 that the synchronism is lost by this abrupt start-up of the DC motor which cause the load to stall. It is important to keep in mind this problem when designing the coupling. Of course, for a lower value of the air-gap, the synchronism would be kept. One can observe in Fig. 16 that the simulation and test results are in close agreement.

\section{E. Transient Performance With Load Variation}

The transient performance with an abrupt application of a load torque is now studied. Before the load torque is applied, the DC motor is in steady-state condition and rotates with a speed of around $750 \mathrm{rpm}$ (under no-load condition). Two cases are interesting to study: torque variation lower or 
greater than the pull-out torque. In one case, we don't lose the synchronism, while in the other case the synchronism will be lost. For these tests, the air-gap value is fixed to $e=$ $20 \mathrm{~mm}$ that corresponds to a pull-out torque of around $6 \mathrm{Nm}$ as shown in Fig. 7d. A schematic view of the test bench arrangement is given in Fig. 17. A DC generator is used to apply the sudden load torque by connecting a resistance to its terminals armature winding.

First of all, a sudden load torque of $4 \mathrm{Nm}$ is applied to the system at $\mathrm{t}=0 \mathrm{~s}$ as shown in Fig. 18 (a load torque of $4 \mathrm{Nm}$ corresponds to a DC current in the generator of $3 \mathrm{~A}$, the torque coefficient of the DC generator being equal to $1.35 \mathrm{Nm} / \mathrm{A}$ ). This load disturbance corresponds to $2 / 3$ of the load which causes the synchronism loss. Fig. 18 shows the speed responses and the DC current in the generator. It can be seen that the settling time of the DC current is very fast compared to the speed variations. After a transient of around $0.3 \mathrm{~s}$, the two speeds are stable again and are synchronous. For this test, the synchronism is not lost.

Fig. 19 shows the speed responses (simulation and experimental results) that follow a sudden application of a load torque of $13.5 \mathrm{Nm}$ at $\mathrm{t}=0 \mathrm{~s}$ (DC current of $10 \mathrm{~A}$ ) which is sufficient to cause the synchronism loss (overload condition).

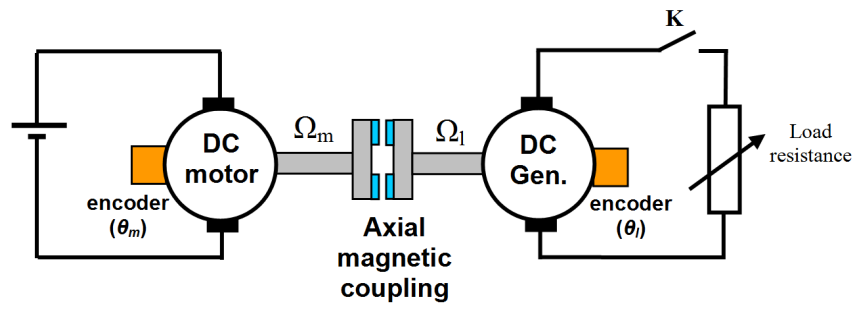

Fig. 17. Test bench arrangement for sudden application of load torque.

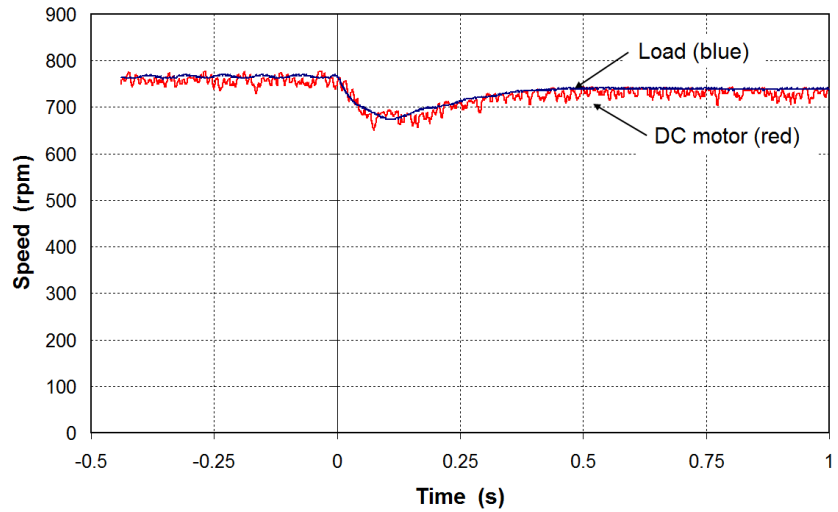

(a)

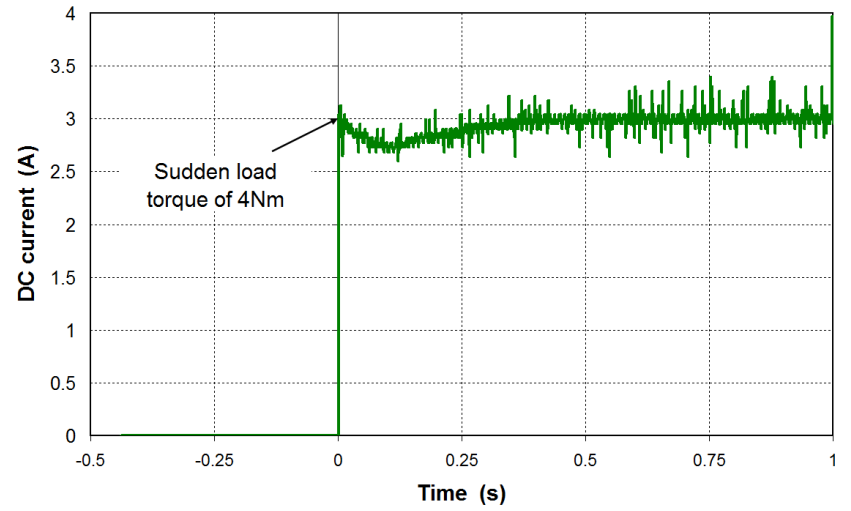

(b)

Fig. 18. Speed responses to a sudden load torque of $4 \mathrm{Nm}$ with $e=20 \mathrm{~mm}$ : (a) motor and load speeds, (b) current in the dc generator (experimental)
As shown in Fig. 19, the speed of the DC motor is maintained at around $750 \mathrm{rpm}$ (after some oscillations) while the load side of the coupling stops. This test clearly shows the overload self-protection of the magnetic coupling. On Fig. 19a, we can observe speed oscillations on the load side around a zero mean value. This 'sinusoidal' speed oscillation is caused by the torque variation given by (15) after overloading. The oscillations frequency can be predicted easily as the product of the DC motor speed in rps $(750 / 60=$ $12.5 \mathrm{rps}$ ) by the number of pole pair of the magnetic coupling $(p=6)$. This gives a frequency of $75 \mathrm{~Hz}$ (around 19 periods between $0.5 \mathrm{~s}$ and $0.75 \mathrm{~s}$ as shown in Fig. 19a). This frequency is also present in the DC motor speed. This signal can be used by a controller to detect an overloading condition as it is shown in [28] for magnetic gears.

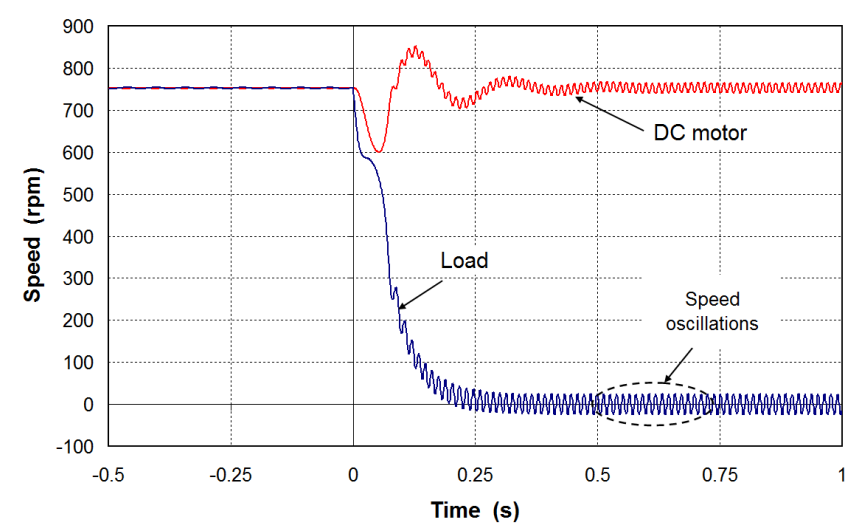

(a)

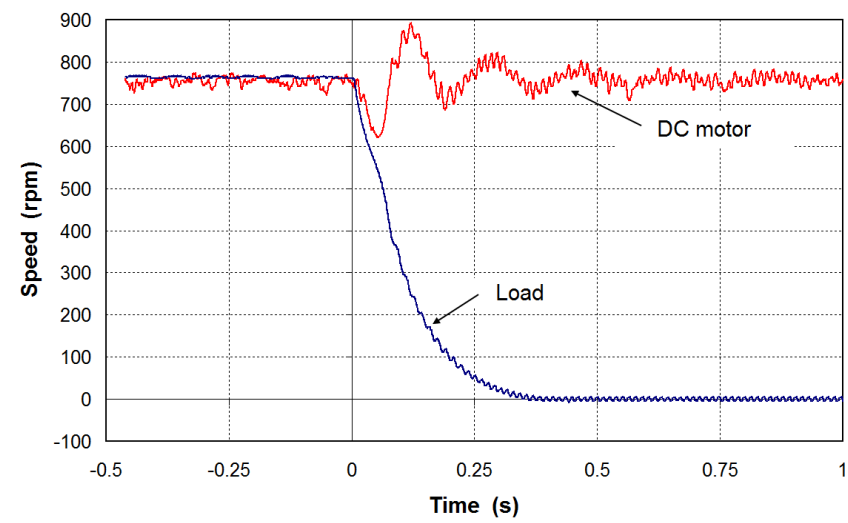

(b)

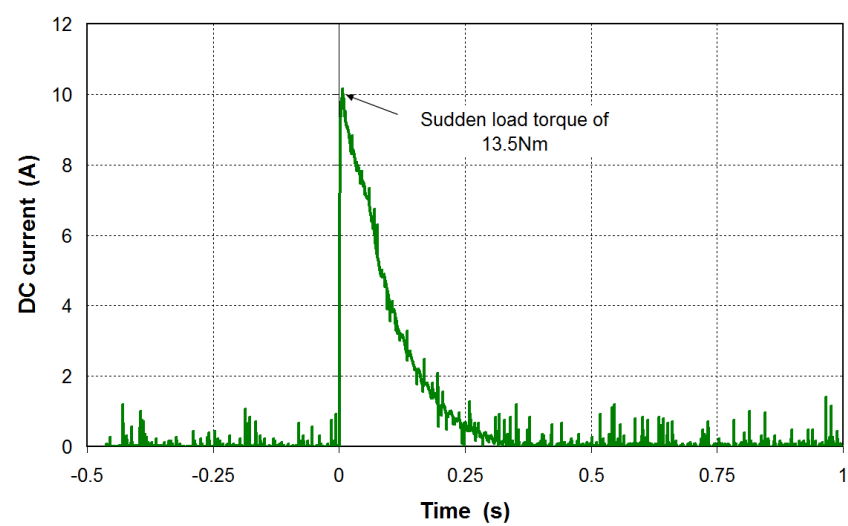

(c)

Fig. 19. Speed responses to an overload condition (sudden load torque of $13.5 \mathrm{Nm}$ with $e=20 \mathrm{~mm}$ ): (a) simulation, (b) experimental results, (c) electrical current in the dc generator (experimental). 


\section{CONCLUSIONS}

By using analytical formulas for the pull-out torque and for the torsional stiffness, both the steady-state and the transient performances of an axial magnetic coupling have been studied in this paper. The proposed 2D analytical model, which is very fast to perform, presents some lack of accuracy compared to 3D finite-element simulations and experimental results (error of around $25 \%$ on the pull-out torque prediction). To improve the predictions, a correction factor $k_{c}$ has been introduced in the pull-out torque formula. Through detailed transient analysis and experimental results, we have shown that the magnetic coupling causes speed oscillations with time delays between the two rotors during start-up. This is due to the low value of the torsional stiffness inherent to magnetic couplings. This must be taken into account for servomechanism applications and every transient behavior. Finally, we have verified by simulation and by tests the overload self-protection of the magnetic coupling.

\section{REFERENCES}

[1] A. Rezzoug, and F. M. Sargos, "Three dimensional field computation of charged sectors: a semi-analytical method," IEEE Trans. Magn., vol. 23, no. 4, pp. 1978-1984, Jul. 1987.

[2] J. P. Yonnet, S. Hemmerlin, E. Rulliere, and G. Lemarquand, "Analytical calculation of permanent magnet couplings," IEEE Trans. Magn., vol. 29, no. 6, pp. 2932-2934, Nov. 1993.

[3] E. P. Furlani, R. Wang, and H. Kusnadi, "A three-dimensional model for computing the torque of radial couplings," IEEE Trans. Magn., vol. 31, no. 5, pp. 2522-2526, Sept. 1995.

[4] Y. D. Yao, G. J. Chiou, D. R. Huang, and S. J. Wang, "Theoretical computations for the torque of magnetic coupling," IEEE Trans. Magn., vol. 31, no. 3, pp. 1881-1884, May. 1995.

[5] J. F. Charpentier and G. Lemarquand, "Optimal design of cylindrical air-gap synchronous permanent magnet couplings," IEEE Trans.Magn. vol. 35, no. 2, pp. 1037-1046, Mar. 1999.

[6] P. Pfister and Y. Perriard, "Very-high-speed slotless permanent-magnet motors: Analytical modeling, optimization, design, and torque measurement methods", IEEE Trans. Ind. Electron., vol. 57, no. 1, pp.296-303, Jan. 2010.

[7] R. Ravaud, V. Lemarquand, and G. Lemarquand, "Analytical design of permanent magnet radial couplings," IEEE Trans. Magn., vol. 46, no. 11, pp. 3860-3865, Nov. 2010.

[8] R. P. Praveen, M. H. Ravichandran, V. T. S. Achari, V. P. J. Raj, G. Madhu, and G. R. Bindu, " A novel slotless halbach-array permanentmagnet brushless DC motor for spacecraft applications ", IEEE Trans. Ind. Electron., vol. 59, no. 9, pp. 3553-3560, Sept. 2012.

[9] J. P. C. Smeets, T. T. Overboom, J. W. Jansen, and E. A. Lomonova, "Modeling framework for contactless energy transfer systems for linear actuators", IEEE Trans. Ind. Electron., vol. 60, no. 1, pp. 391-399, Jan. 2013.

[10]F. Weizhong, and P. C. K. Luk, "Torque ripple reduction of a directdrive permanent-magnet synchronous machine by material-efficient axial pole pairing", IEEE Trans. Ind. Electron., vol. 59, no. 6, pp. 2601-2611, Jun. 2012.

[11]A. Di Gerlando, G. M. Foglia and M. F. Iacchetti, "FEM2D based analytical model of the air gap magnetic field in surface PM synchronous machines", Proc. 20th Int. Conf. Elect. Mach. (ICEM), pp. 2832-2838, Sep. 2012.

[12]L. Belguerras, L. Hadjout, T. Lubin, S. Mezani and A. Rezzoug, "Analytical computation of flux concentration PM machines: study of the influence of the magnets shap", Proc. 20th Int. Conf. Elect. Mach. (ICEM), pp. 2752-2758, Sep. 2012.

[13]L.J. Wang, L. Hu, K. M. Lee, X. D. Ruan, and X. Fu, "Analytical magnetic field and driving force models based on measured boundary conditions for industrial coriolis mass flowmeters", IEEE Trans. Ind. Electron., vol. 59, no. 12, pp. 4753-4760, Dec. 2012.

[14]W. Xie, G. Dajaku and D. Gerling, "Analytical method for predicting the air-gap flux density of dual-rotor permanent-magnet (DRPM) machine", Proc. 20th Int. Conf. Elect. Mach. (ICEM), pp. 2766-2771, Sep. 2012

[15]K. Boughrara, R. Ibtiouen, and O. Touhami, "Exact analytical prediction of magnetic field in a hybrid and wound excitation synchronous machine", Proc. 20th Int. Conf. Elect. Mach. (ICEM), pp. 2818-2824, Sep. 2012.

[16]L. J. Wu, Z. Q. Zhu, D. A. Staton, M. Popescu, and D. Hawkins, "Comparison of analytical models of cogging torque in surfacemounted PM machines", IEEE Trans. Ind. Electron., vol. 59, no. 6, pp. 2414-2425, Jun. 2012.

[17]T. Lubin, S. Mezani, and A. Rezzoug, "2D analytical calculation of magnetic field and electromagnetic torque for surface-inset permanent magnet motors," IEEE Trans. Magn., vol. 48, no. 6, pp. 2080-2091, Jun. 2012.

[18]J. Krotsch and B. Piepenbreier, "Radial forces in external rotor permanent magnet synchronous motors with non-overlapping windings," IEEE Trans. Ind. Electron., vol. 59, no. 5, pp. 2267-2276, May 2012.

[19]J. Fontchastagner, Y Lefèvre, and F. Messine, "Some co-axial magnetic couplings designed using an analytical model and an exact global optimization code," IEEE Trans. Magn., vol. 45, no. 3, pp. 1458-1461, Mar. 2009.

[20]T. Lubin, S. Mezani, and A. Rezzoug, "Simple analytical expressions for the force and torque of axial magnetic couplings," IEEE Trans. Energy. Convers., vol. 27, no. 2, pp. 536-546, Jun. 2012.

[21]N. Niguchi, and K. Hirata, "cogging torque analysis of magnetic gear", IEEE Trans. Ind. Electron., vol. 59, no. 5, pp.2189 -2197, May 2012.

[22]C. Ferreira and J. Vaidya, "Torque analysis of permanent magnet coupling using 2D and 3D finite elements methods," IEEE Trans. Magn., vol. 25, pp. 3080-3082, Jul. 1989.

[23]W. Wu, H. C. Lovatt, and J. C. Dunlop, "Analysis and design optimisation of magnetic couplings using 3D finite element modelling," IEEE Trans. Magn., vol. 33, no. 5, pp. 4083-4085, Sept. 1997.

[24]R. Wang, E. P. Furlani, and Z. J. Cendes, "Design and analysis of a permanent magnet axial coupling using $3 \mathrm{D}$ finite element field computations," IEEE Trans. Magn., vol. 30, no. 4, pp. 2292-2295, Jul. 1994.

[25]Y. Kano, T. Kosaka, and N. Matsui, "A simple nonlinear magnetic analysis for axial-flux permanent-magnet machines", IEEE Trans. Ind. Electron., vol. 57, no. 6, pp.2124 -2133, Jun. 2010.

[26]K. T. Chau, D. Zhang, J. Z. Jiang, and L. Jian, "Transient analysis of coaxial magnetic gears using finite element comodeling," J. Appl. Phys., vol. 103, 07F101, 2008.

[27]N. W. Franck, S. Pakdelian, and H. A. Toliyat, "Passive suppression of transient oscillations in the concentric planetary magnetic gear," IEEE Trans. Energy. Convers., vol. 26, no. 3, pp. 933-939, Sept. 2011.

[28]R. G. Montague, C. M. Bingham, and K. Atallah, "Servo control of magnetic gears," IEEE/ASME Trans. Mechatronics., vol. 17, no. 2, pp. 269-278, Apr. 2012.

[29]T. Lubin, S. Mezani and A. Rezzoug, "Steady-state and transient analysis of an axial flux magnetic coupling", Proc. 20th Int. Conf. Elect. Mach. (ICEM), pp. 1443-1449, Sep. 2012.

[30]H. Toda, Z. Xia, J. Wang, K. Atallah, and D. Howe, "Rotor eddycurrent loss in permanent magnet brushless machine," IEEE Trans. Magn., vol. 40, no. 4, pp. 2104-2106, Jul. 2004.

[31]L. Alberti, E. Fornasiero, N. Bianchi, and S. Bolognani "Rotor losses measurements in an axial flux permanent magnet machine," IEEE Trans. Energy. Convers., vol. 26, no. 2, pp. 639-645, Jun. 2011.

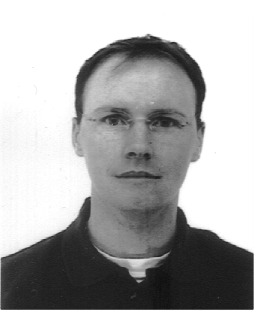

Thierry Lubin was born in Sedan, France, in 1970. He received the M.S. degree from the University Pierre et Marie Curie, Paris 6, France in 1994 and the Ph.D. degree from the University Henri Poincaré, Nancy, France, in 2003.

$\mathrm{He}$ is currently a lecturer of Electrical Engineering at the University of Lorraine, at the Groupe de Recherche en Electrotechnique et Electronique de Nancy. His interests include modeling and control of electrical machines, and applied superconductivity in electrical devices.

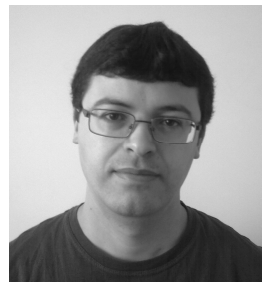

Smail Mezani was born in Algiers, Algeria, in 1974. He received the engineer diploma and the magister degree from the University of Sciences and Technology Houari Boumediene, Algiers, Algeria in 1996 and 1999 respectively. He obtained the Ph.D. degree from the Institut National Polytechnique de Lorraine, France, in 2004. He is currently a lecturer at the University of Lorraine, France, at the Groupe de Recherche en Electrotechnique et Electronique de Nancy where his research interests include the applications of superconductors in electromechanical devices. 
Abderrezak Rezzoug received the electrical engineer degree from ENSEM INPL, Nancy, France in 1972, and the Dr. Ing. diploma and the Ph.D. degree from INPL, in 1979 and 1987 respectively.

After working at the INPL as an assistan Professor until 1991, he is currently a Professor of Electrical Engineering at the University of Lorraine, France. As a member of the Groupe de Recherche en Electrotechnique et Electronique de Nancy, his main subjects of research concern superconducting applications to electrical devices, and the control and diagnosis of electrical machines. 